\title{
Espaço e Diferenciação Funcional ${ }^{1}$
}

\author{
À memória do Compadre João
}

Pierre Guibentif ${ }^{2}$

\begin{abstract}
Resumo: No tratamento do espaço, a sociologia não pode deixar de ter em conta os resultados dos trabalhos que incidem na diferenciação funcional. Uma consequência desta é que se desfizeram as ligações que poderão ter existido em contextos pré-modernos, entre a construção do espaço e a construção de colectivos humanos. Por um lado, a produção do espaço passa a corresponder a determinadas funções sociais. Por outro lado, são produzidos espaços em função dos colectivos cuja emergência ou manutenção poderão facilitar. A partir deste modelo, são propostas algumas reflexões exploratórias sobre as transformações actuais da nossa experiência social do espaço.
\end{abstract}

Palavras-chave: Espaço; Território; Espaço público; Diferenciação funcional; Estado.

Um dos principais temas do pensamento sociológico desde que se estabeleceu como disciplina académica tem sido a chamada diferenciação funcional, ou seja a separação entre vários domínios de actividade social que, embora sejam componentes de um mesmo colectivo, obedecem cada um a uma lógica própria. Com efeito, o tratamento deste tema é indispensável à justificação, por um lado, de um trabalho de reflexão sobre as práticas sociais conduzido nas universidades, isto é, fora dos contextos destas práticas; por outro lado, permite dar conta do lugar da sociologia entre as várias outras ciências sociais, entre as quais várias incidem, precisamente, em domínios especializados de actividade, nomeadamente a economia e a ciência jurídica.

No entanto, o tratamento do tema da diferenciação funcional tem encontrado várias dificuldades. Em muitas circunstâncias, a gravidade dos problemas sociais tem obrigado os sociólogos a dar prioridade ao estudo das desigualdades sociais, $o$ outro grande tema tradicional da disciplina. A existência de outras disciplinas tratando os domínios especializados tem-na, por vezes, dissuadido em avançar num trabalho que necessariamente ia tocar em terrenos que se podia considerar como reservados a estas outras disciplinas. Esta situação veio, mais tarde, a complicar-se de alguma forma com a especialização interna da disciplina. A criação de subdisciplinas especializadas no tratamento de vários destes domínios especializados - religião, educação, saúde, etc. - se significava um reconhecimento por assim dizer institucional da tese da diferenciação funcional, também dispersava os lugares onde se podia aprofundar a sua discussão. Finalmente, o tratamento deste tema é dificultado, ainda, pelo facto de obrigar a sociologia, assim como qualquer disciplina científica, a confrontar-se com as suas próprias condições de definição. Será que a sociologia pode, em rigor, questionar a diferenciação funcional quando ela própria é um resultado desta?

Circunstâncias propícias para o aprofundamento deste tema são as que estão na base do presente artigo: um desafio lançado por um artista a um sociólogo para participar numa reflexão comum sobre a realidade social, mais especificamente sobre o que poderá ser chamado "espaço público". Circunstâncias propícias porque ambas, a arte e a ciência, nas suas versões modernas, são reconhecidas como domínios diferenciados; mais, como domínios que se teriam diferenciado num mesmo processo. Na reflexão sobre este processo,

\footnotetext{
${ }^{1}$ Uma primeira versāo destas reflex̋es foi apresentada, sob o título "Partilhar, estruturar, percorrer, imaginar - Experiências sociais e individuais do espaço", no Porto em Abril de 2006, no seminário "Em torno do espaço público", organizado pelo coreógrafo André Guedes no âmbito do Projecto Em Torno. Queria expressar aqui, mais uma vez, o meu reconhecimento ao André Guedes pelo desafio excepcionalmente motivador que me lançou, e à Vanda Gorjão, graças a quem me encontrei envolvido nesse projecto.

2 Professor no ISCTE e na Faculdade de Direito da Universidade Nova de Lisboa; contacto: pierre.guibentif@iscte.pt
} 
o diálogo entre arte e ciência facilita às duas partes um ponto de vista distanciado sobre a sua própria posição. O tema proposto é, deste ponto de vista, particularmente favorável, pois tanto a arte como as ciências, entre as quais a sociologia, participam na construção social do espaço.

Ao mesmo tempo, abordar o espaço através de teoria da diferenciação funcional é uma oportunidade de aprofundar a apreciação de ofertas teóricas que têm sido pouco aplicadas a estas matérias, em particular a teoria dos sistemas, e de contribuir, desta maneira, para a discussão da teoria sociológica do espaço.

\section{Construção de espaços, construção de colectivos}

Com tudo o que este tipo de exercício tem de questionável, vale a pena iniciar o raciocínio por algumas reflexões sobre a relação entre espaços e colectivos em contextos pré-modernos. Admitimos que, nesses contextos, poderá ter existido reciprocidade entre dois processos: a construção do espaço, por um lado, e a construção de colectivos, por outro. O espaço é o meio onde o colectivo subsiste; é definido em função das actividades necessárias à reprodução desta. Se depende da criação de gado, deverá haver distribuição dos terrenos entre os que possuem os rebanhos. A palavra "voнoc" em grego, que significa a lei que vigora entre os humanos, teria designado inicialmente o costume que atribuía determinado lugar a um proprietário de gado, para pasto. Teria na sua raiz uma hipotética palavra "nem" que estaria também na origem da palavra alemã "nehmen", "tomar para si"3. Esta etimologia revela uma estreita ligação entre a experiência de um determinado espaço e a noção que se tinha da divisão do trabalho produtivo. Outro espaço que se pode experienciar é o que se pode defender, onde se pode estar protegido, espaço que pode ser eventualmente estendido por conquista. As civilizações antigas terão assentado numa articulação entre estes dois tipos de espaço. Um rei, ou o colectivo de alguma maneira instituído, procura defender e eventualmente ampliar pelas armas uma zona que, por sua vez, compreende vários domínios explorados para a produção agrícola. Uma tal articulação de espaço defendido e de espaço produtivo foi possível onde se conseguiu juntar pessoas para organizar as medidas de defesa e os meios materiais necessários para esta defesa ${ }^{4}$. Esta junção de pessoas poderá conduzir à formação de um terceiro tipo de espaço, a cidade, um espaço comum (Agier, 2008). Estes três tipos de espaços são definidos pelas práticas que são necessárias à reprodução do colectivo: produzir, defender, conviver.

Inversamente, o espaço permite a identificação do colectivo e das pessoas que a compõem. Estas podem ser identificadas em função do lugar ou da cidade de onde vêm; o seu estatuto é especificado pela actividade que desempenham no espaço: cultivá-lo ou defendê-lo. Também podem ser identificadas pela ausência de um vínculo firme com o espaço: como viajantes, negociantes ou vagabundos. O espaço social, para utilizar a metáfora de Pierre Bourdieu (1994), é idêntico ao espaço físico.

O processo circular de definição do espaço pelas práticas sociais, e de definição do colectivo pelo espaço poderá ter sido intensificado por práticas religiosas. Estas, com efeito, caracterizam-se pela definição, no meio do espaço onde vive o colectivo, de um espaço mais restrito, mais claramente delimitado, ao qual apenas um grupo mais restrito de pessoas tem acesso, e onde os gestos e ditos dos membros deste grupo podem revestir um sentido mais nítido para todos os demais elementos do colectivo 5 . 0 templo reintroduz no seio do colectivo uma representação da mecânica pela qual o colectivo em geral se situa, se delimita e se reproduz, reforçando as categorias de "limite", de "pertença", de "gesto necessário" requeridas para que as práticas diárias produzam, na experiência de cada um, precisamente as noções de espaço e de colectivo ${ }^{6}$.

Um sociólogo não pode deixar de concluir esta reconstrução sumária das raízes dos processos de construção do espaço e dos colectivos sem sugerir que a construção do colectivo poderá ter sido o primeiro passo na evolução, prévio à construção do

\footnotetext{
3 Ver Chantraine (1968), entrada ' $v \varepsilon \mu \omega$ '.

4 Sobre a formação de colectivos e sua relação com o espaço na antiguidade, ver em particular os trabalhos de Finley ([1970]1980; [1983]1985), nomeadamente a sua análise do desenvolvimento de Esparta ([1970]1980), pp. 131ss.

${ }^{5}$ Neste sentido, Meeks / Favard-Meeks (1995), p.161 s.

${ }^{6}$ Sobre a discussão das relações entre religião e economia, na qual este modelo se inspira, ver Iturra (2002).
} 
espaço. Os colectivos nómadas dificilmente poderiam ter-se apoiado em experiências do terreno em que viviam para definirem quais os seus membros e as relações entre estes. Mais provavelmente terão sido as relações entre as pessoas que terão merecido consolidação simbólica, e o seu não respeito sanções muito severas ${ }^{7}$ Uma vez estabilizada a percepção destas relações, estão criadas as condições para uma percepção estruturada do espaço: espaços que separam as pessoas (percepção que pressupõe uma noção de relação entre duas pessoas); lugar para onde uma pessoa se pode dirigir junto com outra pessoa; deslocações no espaço, por referência às outras pessoas que se deslocam ou não, etc. As referências espaciais na identificação dos colectivos parecem no entanto desempenhar um papel crucial no desenvolvimento das civilizações. Assim, a história narrada pelo Pentateuco do povo judeu é a da sua procura da "terra prometida", aliás geograficamente situada. Na Grécia antiga, a Ilíada e a Odisseia podiam ser lidas - aliás ouvidas - como narrativas da busca, pelos humanos, de um espaço de referência (cidade que se conquista, casa onde se regressa). A epopeia de Gilgamesh talvez ilustre da maneira mais directa o nascimento da consciência humana num discurso onde são tanto as relações entre homens que definem os espaços, como os espaços que definem as relações entre homens: à relação entre cidade e terra selvagem corresponde a luta e depois a amizade entre os heróis Gilgamesh e Enkidu; a amizade e a igualdade entre os dois materializa-se na longa viagem de Uruk-Mesopotâmia à floresta de cedros-Líbano (s.a., 1989).

\section{Diferenciação funcional, construção do espaço, construção do território}

O ponto de partida do raciocínio que se segue é que a diferenciação funcional participa de uma evolução na qual os dois processos - construção de espaços e construção de colectivos - se separam. Trata-se aqui de recordar como se processa esta separação e quais são as suas implicações.
Examinaremos nas duas secções que se seguem o período de evolução que podemos observar com algum distância. Dedicaremos algumas reflexões exploratórias à época actual - a "pós-modernidade" - na última secção.

Aceita-se aqui como ponto de partida a tese defendida por Jürgen Habermas, e implicitamente reconhecida por Niklas Luhmann, segundo a qual um primeiro processo de diferenciação funcional consiste na diferenciação dos discursos científicos, artísticos e jurídicos ${ }^{8}$, num processo longo que se estende aproximadamente do Renascimento às Revoluções burguesas. Uma característica destes três discursos é que não são definidos territorialmente. Dirigem-se ao mundo inteiro. O que é uma característica - no que diz respeito à produção escrita - ligada à generalização da imprensa e à possibilidade de divulgar, com alguma facilidade, livros em todos os lugares onde há leitores. Um fenómeno que manifesta com particular nitidez como esta diferenciação funcional significou uma emancipação em relação ao espaço é o surgimento da novela, que coloca o seu leitor deliberadamente num lugar imaginário, isto é, fora do espaço99.

Esta tese mereceria ser melhor precisada e justificada. Aqui, limitar-nos-emos a duas especificações. Quando se fala em diferenciação de um direito para além de fronteiras territoriais, é por referência a um discurso sobre o direito, o seu papel nos Estados, e a importância dos direitos subjectivos das pessoas e da codificação destes direitos, e não por referência aos direitos positivos nacionais, noção que, aliás, surge apenas no fim do período a que nos referimos. Quando se fala em circulação de obras de arte, deveria especificar-se o sentido que esta expressão reveste no domínio das artes figurativas: não tanto um circular material das obras, mas a possibilidade destas obras, onde quer que tenham sido produzidas e instaladas, poderem ser apreciadas - eventualmente em termos polémicos - em todos os lugares com critérios análogos.

A diferenciação da ciência, do direito e da arte conduz a dispositivos que também podem ser

\footnotetext{
7 Ver, para tomar o exemplo do povo judeu na alta antiguidade, a pena de lapidação prevista para o filho "indócil e rebelde" (Deuteronómio, 21 , 18-20).

${ }^{8}$ Habermas fala de diferenciação dos componentes da Lebenswelt, segundo as três "pretensões de validade", verdade, autenticidade, e validade normativa (Habermas, 1981, vol. 2, pp. 290 - 214; 584 - 437). Luhmann dedica três volumes da sua série de livros sobre a sociedade contemporânea respectivamente à ciência (1990), ao direito (1993) e à arte (1995). O primeiro dos sistemas diferenciados tratado, em 1988, é a economia, mas Die Wirtschaft der Gesellschaft não deu lugar a um trabalho de sistematização teórica tão aprofundado como o que sustenta os volumes seguintes, já que é composto, em boa parte, por artigos já publicados anteriormente.

9 Também se poderia referir aqui a importância que adquire, neste mesmo período, o motivo da utopia.
} 
vistos como construindo circularmente um mundo e um colectivo. Porém, já não se trata de espaços concretos e de colectivos localizáveis. O mundo que se pretende abranger é o universo, e o colectivo que se experiencia no trabalho de conhecimento deste universo é a humanidade. Humanidade que se concretiza num colectivo de indivíduos dotados dos mesmos instrumentos cognitivos, indivíduos que, por isso, independentemente das suas origens e da sua localização concretas, podem entender-se sobre uma mesma visão do mundo. A noção destes indivíduos abstractos tem um fundamento histórico: a existência de uma população de pessoas instruídas que circulavam entre as grandes cidades europeias e que eram reconhecidas pelo saber que lhes proporcionava o acesso a diversas culturas. É precisamente uma pessoa com estas características que relata a Tomás Morus a utopia (Morus [1516] 1952, p. 25).

Com este processo de diferenciação, abre-se uma clivagem entre uma minoria de pessoas directamente envolvidas na produção destes discursos diferenciados, ou acompanhando-a de perto, e uma maioria, que apenas pode assistir de longe às discussões sábias, ou as ignora completamente.

Este processo permite separar, para quem tem acesso aos discursos diferenciados que dele resultam, por um lado, a identificação de pessoas e das relações entre estas e, por outro, a relação com espaços específicos. A identidade pertinente para construir uma relação é a que confere a pertença à categoria de homem de ciência, de "especialista em questões de direito político" (Morus [1516] 1952, p. 23), ou de artista. A relação com o espaço não deixa de existir, mas passa a ser um componente da relação com o mundo. O que tem duas implicações. Por um lado, o espaço surge agora como um objecto de um conhecimento específico ao lado de outros (a história, as línguas, a natureza, etc.). Por outro, passa a ser objecto de um conhecimento próprio, independente da posição e das necessidades concretas de quem participa na sua elaboração. Neste plano mais específico, a construção do espaço e a construção de um colectivo desligam-se. $\mathrm{O}$ espaço é construído - conhecido, pensado - não em relação directa com uma experiência da vida colectiva de um colectivo em particular, mas porque se considera necessário, para o conhecimento da condição humana em geral, haver um bom conhecimento do espaço. Kant, numa obra dedicada à "geografia física", afirmava que "não se pode conhecer o homem se não se conhece o meio onde vive" ${ }^{\text {"10 }}$. Formar-se-á, sim, uma comunidade dos que estudam o espaço - astrónomos, geógrafos, etc. - e esta será vivida não como um colectivo no sentido tradicional, mas como um conjunto de relações especializadas, por definição parte, apenas, de um conjunto mais amplo de relações sociais ${ }^{11}$.

Esta evolução também se pode acompanhar no domínio artístico. Exprime-se de maneira particularmente clara no tratamento das paisagens na pintura. Recordemos brevemente algumas etapas. Numa fase que antecede o Renascimento, as paisagens são elementos acessórios do pano de fundo. No Renascimento, a paisagem, assim como o meio material mais próximo das figuras principais, são tratados como parte integrante da construção do quadro, aproveitando-se as perspectivas para valorizar os motivos principais. O quadro já é composto com a consciência que irá ser apreciado por outro indivíduo culto, capaz de se recolocar, seguindo as indicações dadas pela perspectiva, na precisa posição do pintor, e, logo, de apreciar criticamente a sua percepção do espaço. Mais tarde, a própria paisagem, tratada com rigor nas perspectivas, e com a preocupação de realismo, torna-se ela própria objecto de quadros, que passam a assumir a vocação de alimentar, no público, as representações do espaço ${ }^{12}$.

Embora os conteúdos dos discursos científicos, jurídicos e artísticos possam circular sem estarem limitadas a um determinado espaço (as medidas dos governantes para travar esta circulação nas fronteiras dos seus países confirmam a possibilidade desta circulação), são no entanto produzidos no âmbito de entidades que, essas sim, estão localizadas espacialmente (academias, editoras, etc.). Mais, o espaço, pela instalação destas entidades em vários locais, pela menção posta em evidência do destino dos imóveis que as acolhem, é utilizado para sinalizar a diferenciação funcional (pense-se em particular nas diferentes instalações

\footnotetext{
$\overline{10}$ Citado por Dortier (1998), p. 419.

11 Ver, como exemplo, o caso dos juristas na Europa dos séculos XVII e XVIII, analisado por Arnaud (1991, pp. 113 ss.). Este autor insiste justamente num motivo que não pode ser aprofundado aqui, a noção de pluralismo que surge da experiência desta comunidade de homens de saber, motivo também realçado, a propósito da mesma época na evolução da cultura jurídica, por Hespanha (2002).

12 Sobre a importância da noção de perspectiva na razão moderna, ver Bourdieu (1997), p. 33 s., citando Panofsky (1975).
} 
de academias das Belas-Artes, por um lado, e das ciências por outro). Esta ancoragem espacial da produção de discursos com vocação universal vai ainda reforçar-se na fase que se vai abordar a seguir, na qual os Estados se apropriam de tal produção.

Para retomar uma periodização proposta noutro artigo (Guibentif, 2005), este processo de diferenciação, ao gerar um discurso não mais definido na relação com um mundo ordenado pela vontade divina, mas sim sustentando-se a si próprio pelas diferenças que reconhece no seu próprio conteúdo, diferenças que simbolizam a sua capacidade em introduzir ordem nas coisas que designa, conduz ao que se poderá chamar a primeira modernidade ${ }^{13}$.

A evolução que se acaba de descrever sumariamente cruza-se com outra: a formação dos Estados modernos. Uma linha desta evolução consistiu na progressiva tomada de controlo, pelos soberanos, sobre um determinado território, território que passou a ser considerado como parte integrante da definição do Estado ${ }^{14}$. Em parte, esta tomada de controlo fez-se aproveitando o então recente desenvolvimento das ciências. Um aproveitamento das ciências que se verificou também noutros domínios como o controlo das populações ou o reforço das forças militares à disposição do soberano. Na perspectiva de controlar em particular o espaço, os Estados cedo concederam apoios à geografia, assim como a outras disciplinas científicas, fornecendo os meios materiais necessários à sua prática, com a contrapartida de estas disciplinas passarem a ter uma vocação agora mais específica do que no racionalismo humanista: fornecer um conhecimento detalhado de um determinado espaço, que possa fundamentar acções visando a melhor afirmação da pertença deste espaço ao Estado, a sua melhor defesa, ou a sua melhor rentabilização. Desta maneira, a ciência passou a produzir, já não apenas espaço, mas, em primeira linha, territórios nacionais.

Os Estados não vão apenas formar-se pelo conhecimento do território, mas também pela sua gestão material. O que consistiu nomeadamente na distribuição das tarefas de intervenção ao nível local a entidades também implantadas localmente, subordinadas ao Estado central ${ }^{15}$. Também foram criadas e dotadas de meios de acção entidades encarregues de contribuir a diversos títulos para o que se poderia chamar a sua produção material. Nomeadamente pela construção de infra-estruturas facilitando a circulação, tanto dos agentes como dos sujeitos do soberano, por todo o território. Os conhecimentos técnicos requeridos para este trabalho também passaram a ser produzidos por disciplinas científicas, desde a física à engenharia civil.

Como é sabido, este desenvolvimento do Estado pela apropriação-produção do território foi acompanhado por - e procurou estimular - uma transformação das actividades económicas. Foi-se precisando o estatuto dos que podiam intervir em transacções mercantis, controlando mais apertadamente os lugares destinados a facilitar estas transacções - os mercados, as feiras -, disciplinando o uso da moeda e o sistema bancário, etc. E os Estados participaram nos desenvolvimentos tecnológicos que conduziram à industrialização ${ }^{16}$. Estes desenvolvimentos paralelos dos Estados e da actividade económica conduziram a uma diferenciação que veio acrescentar-se à que gerou a ciência, o direito e a arte, dando consistência própria e distinta às administrações estaduais, e contornos mais precisos ao domínio económico.

Este segundo momento de diferenciação também tem implicações para o espaço. $\mathrm{O}$ espaço não é já apenas conhecido por saberes diferenciados; também existem territórios materialmente produzidos pelas intervenções das administrações estaduais e pela actividade económica. Entre as realizações que se podem observar na fronteira entre estes dois desenvolvimentos temos, nomeadamente, os registos prediais, que vão permitir uma atribuição e medição mais nítida dos terrenos, facilitando tanto a sua exploração agrícola ou industrial, como a sua rentabilização financeira.

No processo pelo qual os Estados vão procurar controlar as dinâmicas geradas pelo que se pode chamar a primeira modernidade, as intervenções dizendo respeito ao território vão intensificar-se. Vão empreender-se grandes obras de urbanismo e de engenharia civil, nomeadamente com o intuito de melhorar as condições sanitárias e de facilitar o controlo da população ${ }^{17}$. Mais tarde ainda, o direito será mobilizado para implementar políticas

\footnotetext{
13 Retoma-se assim a tese de Michel Foucault, sobre as características do que chama o discurso da "Idade Clássica" (Foucault, 1966 / s.d. p. 77)

14 Sobre a importância do território no desenvolvimento das práticas de governo, ver em particular Foucault ([1978] 2004).

15 No caso de Portugal, Hespanha (1988) estudou uma fase neste processo, a submissão das jurisdições locais ao poder central.

${ }^{16}$ Entre muitas outras referências sobre as relações entre os Estados e a economia, ver Gonçalves et al. (2001).

${ }^{17}$ Vejam-se a este respeito as análises detalhadas e pertinentes de Chevalier (1978), nomeadamente o capítulo "A população e a cidade" (pp. 344 ss.).
} 
de ordenamento do território, destinadas nomeadamente a distribuir melhor as várias organizações pelo território e a completar o enquadramento da actividade económica.

Nesta mesma fase, os Estados vão reforçar os seus meios de produção científica e - retomaremos este ponto mais adiante - o seu apoio à produção artística, e vão desenvolver a sua ordem de direito positivo. Esta territorialização, na realidade, não afecta na sua essência estes discursos - embora os temas nacionais tenham agora que ser privilegiados: a referência a noções não territorializáveis de ciência, arte e direito, continua necessária para que o estatuto destes discursos possa ser reconhecido em cada país. Mas assiste-se a um reforço do aparelho de organizações que sustenta a sua produção, e a um estreitar da ligação entre o Estado e estas organizações ${ }^{18}$. Neste processo, aliás, o mecanismo da diferenciação pela localização vai ser reforçado (um exemplo: as várias faculdades das universidades). Assim, a diferenciação funcional, inicialmente uma experiência de emancipação em relação ao espaço, vai passar a ser sustentada, principalmente, por entidades situadas territorialmente. É este universo onde territorialização e diferenciação funcional se correspondem que Zygmunt Bauman apelidou, de maneira pertinente, a modernidade sólida (Bauman, 2000).

Tendo-se sintetizado os processos de diferenciação na sua dinâmica por assim dizer interna, deve agora examinar-se como são vividos de fora. Com efeito, o espaço construído por estes vários discursos e sistemas especializados deixa de poder ser conhecido imediatamente e completamente pelo leigo. Para entender completamente uma zona que descobre, uma pessoa deveria dispor de conhecimentos de geografia, geologia, economia, direito, gestão municipal, sobre meios de transporte, eventualmente de literatura, etc., um leque de especialidades que poucos poderão dominar completamente. Abre-se assim uma brecha entre o espaço experienciado pelas pessoas e o espaço tal como pode ser observado de maneira competente pelos especialistas. E dificilmente um especialista, precisamente por ser especialista, poderá conhecer globalmente um determinado espaço.

Neste ponto, a segunda modernidade entra em conflito com a primeira - Habermas falaria em ambivalência da modernidade. Enquanto a primeira modernidade tinha sido um momento de experiência por certos colectivos da sua capacidade de se governarem a si próprias, a segunda modernidade é organizada de tal forma que produz o risco de os membros destes colectivos perderem o conhecimento sobre o mundo em que vivem.

Um mecanismo pelo qual as pessoas têm alguma possibilidade de reconquistar um certo conhecimento do território onde vivem é a comunicação social. Esta, tendo surgido em vários lugares já nos séculos XVII e XVIII, passa a atingir uma parte importante da população durante o século XIX e praticamente a totalidade desta na primeira metade do século XX com a generalização da telefonia ${ }^{19}$. No que diz respeito às relações entre as pessoas e o espaço, a comunicação social pode em particular desempenhar três funções: informar as pessoas do que se passa em vários pontos do território; dar esclarecimentos quanto às várias actividades pelas quais o espaço territorial é tratado, ordenado, ocupado por construções etc.; e fazer conhecer eventos nos quais parte da população se encontrou em lugares públicos, para manifestar ou festejar, permitindo assim ao leitores e ouvintes aderir de alguma forma a estes eventos.

À perda de domínio do espaço pelo conhecimento acrescenta-se o facto de sectores importantes do território serem dedicados às organizações que sustentam as actividades diferenciadas, em primeira linha a economia. Estes deixam, desta maneira, de ser acessíveis à maioria das pessoas. Deveremos reconhecer que sempre houve zonas às quais apenas determinadas pessoas tinham acesso. Porém, na modernidade, estes espaços restritos, além de serem definidos com mais precisão e defendidos mais eficazmente, tendem, no longo prazo, a multiplicar-se.

Os espaços reservados a actividades especializadas são naturalmente acessíveis aos que nelas participam. E podem ser muitas as pessoas que estão nesta situação: pense-se nas escolas e universidades, em lojas, ou, também, nas auto-estradas. No entanto, deve aqui ter-se em conta o facto de estas organizações terem, muitas vezes, estruturas complexas que implicam a distribuição de papéis muito diferentes. Serão relativamente raros os papéis que dão acesso e conferem os

\footnotetext{
${ }_{18}$ Para o caso da justiça, ver Commaille (2000).

19 Para uma qualificação da comunicação social como sistema social funcionalmente diferenciado, ver Luhmann (1996)
} 
conhecimentos que permitam experienciar uma sensação de domínio do espaço organizacional. Para a maioria dos papéis, pelo contrário, a experiência da actividade nas organizações confirmará o que se vive fora destas: cada um movimenta-se num espaço cujo conhecimento lhe é pouco acessível, e que lhe é, enquanto espaço, também fisicamente, pouco acessível.

Para concluir a descrição do papel do Estado na diferenciação funcional e na construção do espaço, não podemos deixar de voltar aos colectivos locais. O processo de progressiva extensão do controlo estadual sobre o território corresponde à intrusão de um determinado modo de gerir o espaço em regiões ou lugares onde até agora prevalecia outro. Em certos lugares esta intrusão equivaleu a uma pura e simples imposição, por vezes suscitando resistências e gerando conflitos. Noutros, optou-se por soluções negociadas ou por procurar meios de compensar as alterações que iam ser impostas aos modos de vida. Uma consistiu em criar ou ampliar espaços oficialmente declarados como públicos. Quem não podia continuar a utilizar determinado atalho, passava a dispor, como todos os outros, de uma estrada ou rua mais cómodas. Poderá referir-se como exemplo deste mecanismo a abertura dos "grands boulevards" em Paris. Esta tinha fundamentalmente motivos policiais e sanitários: garantir um acesso às forças da ordem em bairros que se devia poder controlar bem, e permitir uma melhor circulação do ar e um melhor escoamento da água da chuva. Fez-se aceitar a sua construção mostrando que poderiam embelezar a imagem da cidade e, sobretudo, permitir aos habitantes passear e conviver em melhores condições.

Outra forma de compensar os inconvenientes da ocupação do território por instalações acolhendo actividades funcionalmente diferenciadas é a dos novos lugares que passam a ser promovidos como merecendo ser visitados e desfrutados. Tendo-se grande parte do território tornado física e cognitivamente inacessíveis, facilita-se o acesso a determinadas outras zonas reputadas como encantadoras. Aliás, os lugares assim recomendados, são-no, não raras vezes, invocando as suas características tradicionais, o que também pode contribuir para tornar aceitável uma evolução, que, a longo prazo, levará ao desaparecimento de tais características.

Já registámos que a evolução intelectual que conduz à diferenciação da ciência, do direito e da arte não atingiu toda a população. Devemos agora ter em conta o facto de os Estados terem conseguido apenas parcialmente - e em proporções que variam entre os Estados - controlar os seus territórios. São de distinguir dois fenómenos. Por um lado, em regiões pouco acessíveis poder-se-ão ter mantido formas de viver os espaços e os colectivos característicos de épocas mais remotas. Em Portugal, ainda há pouco tempo, puderam viver-se relações pessoais definidas por um determinado sistema de relações com a terra, e lugares havia que eram identificados com as pessoas que deles cuidavam e lhes imprimiam, pelo seu trabalho perseverante, a sua marca. Por outro lado, depois das Revoluções liberais e com o constitucionalismo, os Estados reconhecem as liberdades pessoais dos cidadãos e, nomeadamente, o direito a uma esfera privada em princípio não submetida ao controlo do Estado. Esta esfera privada corresponde, em larga medida, ao que poderá chamar-se o espaço familiar. Nestes espaços que subsistem assim à margem da ordem estadual, podem manter-se processos tradicionais de construção do espaço pelo colectivo, que por sua vez se constrói a si própria neste mesmo processo.

Vale a pena acrescentar mais um contexto que escapa nalguma medida aos modos estaduais ou aos outros modos formalizados de construção do espaço. Trata-se do contexto que Goffman (1980) chamou a ordem da interacção. A hipótese subjacente ao raciocínio deste autor é que os esforços de gestão do espaço e do tempo de grandes organizações, assim como as formas de relacionamento geralmente aceites num colectivo não podem determinar completamente, nem no tempo, nem no espaço, o que acontece nas "situações" nas quais nos encontramos envolvidos. Existe sempre, nestas situações, alguma margem na qual devemos actuar "nós", aqui e agora. $\mathrm{O}$ que resta em aberto diz respeito, em particular, à gestão do espaço na proximidade. Quem se instala de que lado, a que velocidade andamos, por onde mais precisamente passamos, qual a distância que mantemos uns em relação aos outros? Estas são algumas das muitas decisões que devemos tomar no dia-a-dia nas situações partilhadas com outros. E nestas situações, na medida em que existem estas margens de manobra, também existe alguma margem para cada um ir construindo a sua posição nas relações, e para certos grupos experienciarem as suas características específicas. 
Chegados a este momento, convém fazer um balanço dos processos de construção do espaço em contextos societais funcionalmente diferenciados:

- Em primeira linha, convém registar uma divisão entre espaços onde se poderá falar de uma construção ou produção do espaço ou do território condicionada pela diferenciação funcional, e outros onde continuam a prevalecer modos pouco ou não diferenciados de construção simultânea do espaço e do colectivo ou da interacção que o ocupa.

- Todo o espaço pode ser vivido como distribuindo-se por vários planos, correspondendo cada plano a um sistema funcionalmente diferenciado. Quando se referem sistemas, visam-se, por um lado, discursos, nomeadamente a geografia, a geologia, o direito (em particular o ordenamento do território), e, eventualmente, um ou vários autores considerados como tendo produzido obras de particular força sobre uma determinada região. E visam-se também universos de práticas: de medição, de construção, de manutenção, de qualificação jurídica, de exploração económica.

- Com a consciência de que existem estas actividades e estes saberes especializados sobre o espaço, a relação com o espaço deixa de ser imediata. Sabe-se que outros o conhecem melhor.

- São muitos os sectores reservados ao desempenho de actividades funcionalmente diferenciadas. Quem não estiver habilitado a participar numa determinada actividade fica excluído do seu sector. Ou seja: o espaço funcionalmente diferenciado é um espaço potencialmente exclusivo. Quem para tal estiver habilitado poderá aceder ao espaço, mas na condição, precisamente, de desempenhar as funções que dele se esperam. $\mathrm{Ou}$ seja: o espaço funcionalmente diferenciado é um espaço que impõe normas comportamentais. É obvio que qualquer vida em sociedade impõe normas. Mas em contextos funcionalmente diferenciados, poderemos ter mais normas, e normas diferentes de um sector para o outro. E poderá verificar-se que estas normas são mais constrangedoras, uma vez que, para além de garantirem a paz so- cial, orientam actividades muito específicas, com a justificação de se aplicarem apenas enquanto a pessoa se encontrar no sector reservado ao desempenho da actividade.

- Em relação aos três pontos anteriores, deve reconhecer-se que as possibilidades de gerir o conhecimento do espaço poderá variar muito segundo o grau de instrução, e segundo as actividades que se está habilitado a exercer. Espaço complexo, no sentido técnico da palavra, o espaço produzido pela diferenciação funcional agrava por sua vez as desigualdades sociais ${ }^{20}$.

- Alguns espaços são conhecidos como públicos. O que os caracteriza não é apenas que todos a eles podem aceder, mas também que não são reservados a nenhuma actividade em particular. Aqui poderia fazer-se uma distinção. Por um lado, existem espaços públicos no sentido mais rigoroso da palavra, isto é, destinados a serem ocupados por um grande público: avenidas, grandes praças, etc. Por outro lado, existem espaços públicos no sentido mais amplo, acessíveis a todos, em princípio, mas onde não se acede com facilidade e que serão, por isso, menos frequentados.

\section{Diferenciação funcional e construção de colectivos}

Assumiu-se que uma característica das sociedades funcionalmente diferenciadas é que nestas se desligaram os processos de construção de espaços e os processos de construção de colectivos. Podemos agora identificar melhor os dois momentos desta separação. Um primeiro aconteceu quando o conhecimento do espaço passou a ser objecto de um saber de especialistas que têm uma vocação geral de contribuir para um conhecimento objectivo do espaço, e não um conhecimento relacionado imediatamente com necessidades concretas de um determinado colectivo. $\mathrm{O}$ segundo momento foi a intervenção dos Estados, que procuraram apropriar-se deste trabalho de produção do conhecimento, na perspectiva de acções estaduais de apropriação e controlo de território. Assim, o colectivo é progressivamente substituído por especialistas e, mais

\footnotetext{
${ }^{20}$ Numa investigação sobre as percepções do crime e da justiça, fomos conduzidos a distinguir três posições sociais: os que permanecem fora da complexidade, os que a sofrem e os que a dominam (Guibentif, 2001, 2002). Poderia aplicar-se esta tipologia aqui, substituindo-se a noção de complexidade pela de território produzido pela diferenciação funcional.
} 
tarde, por agentes do Estado, que, de alguma forma em representação de uma comunidade imaginária (a humanidade para os especialistas dos saberes modernos, a nação para os agentes do Estado), participam na construção do espaço. A questão que deve agora ser retomada é: quais são, nestes mesmos contextos históricos, os processos de construção de colectivos? E, se quisermos reconstituir de forma mais abrangente os dispositivos que sucederam aos mecanismos pré-modernos de simultânea construção de espaços e de colectivos, qual o papel do espaço nestes processos?

Uma questão prévia deve ser brevemente recordada: de que colectivo poderá tratar-se? Foram atrás referidas dois colectivos imaginários: a humanidade e a nação. Foram ainda referidos colectivos concretos, que se admitiu terem existido antes da diferenciação funcional, e que poderão subsistir localmente, mas que terão desaparecido de boa parte do espaço onde operam dispositivos funcionalmente diferenciados. Poderemos ainda considerar as realidades que designamos "sociedades" (a "sociedade portuguesa", por exemplo). Mas, também aqui, teremos que discutir concretamente em que consistem tais realidades. Ou seja, voltamos à questão dos colectivos que se constroem nos tempos recentes, questão que devemos tratar sem presumir dos resultados dos processos de construção que observaremos. Teremos que apreciar caso a caso estes resultados, e qualificar os colectivos que poderemos encontrar em função desta apreciação.

Os colectivos, na modernidade, podem ser construídos de várias maneiras, e não apenas na base do espaço. Já nos colectivos pré-modernos, terá havido outros mecanismos. Muito importantes foram os mitos e outras narrativas identificadoras. Mas pode considerar-se que o espaço revestia então mais importância do que nos tempos mais recentes. Nestes, as narrativas identificadoras poderão continuar a ter alguma importância, mas a diferenciação dos discursos permite agora produzir novos conhecimentos sobre determinados colectivos, enunciar para estes novos projectos, suscitar a seu respeito novas emoções. A diversidade destes discursos e a relativa facilidade com que podem ser produzidos faz deles ferramentas de produção de novos colectivos, sendo a existência destas ferramentas a característica da modernidade. De facto, procurou-se construir novas sociedades pelo meio do direito, com constituições, nomeadamente no caso dos Es- tados Unidos da América e da França (Habermas, 1963), ou reescrevendo a história do direito, como no caso da Alemanha (Hespanha, 2003). Também pelo meio da arte, nomeadamente a literatura, com novelas que, sem pretenderem instituir de novo uma sociedade, poderão procurar dar-lhe mais realidade, duplicando-a no imaginário. Um esforço que se justifica particularmente quando existe a sensação que estes colectivos estão a evoluir (pode pensar-se nos romances de Balzac ou de Eça de Queiroz). No domínio da ciência, não podemos deixar de recordar aqui que a vocação implícita da sociologia quando se estabeleceu como disciplina académica foi, precisamente, a de contribuir para que exista uma "sociedade". Os próprios Estados, movidos por políticos que queriam reforçar a consciência dos cidadãos da sua pertença à nação (em França, foi o caso do ideólogos: Gusdorf, 1978), consolidar a sua legitimidade ou garantir a paz social, incentivaram a produção de discursos - assim como de representações artísticas - que pretendiam contribuir para a construção de uma identidade nacional. Entre estes, poderá destacar-se em particular o ensino da História nas escolas.

Convém agora acrescentar um mecanismo particularmente importante de identificação dos colectivos modernos, que, aliás, fascinou Durkheim na sua Divisão do Trabalho Social: a própria diferenciação funcional. É possível construir uma certa imagem da "sociedade" a partir da noção de que existem diferenças entre uma função do Estado e uma actividade económica privada, ou entre discursos como a ciência, o direito e a arte; ou ainda, recorrendo ao indicador em que se apoiou Durkheim, de que existem diferentes profissões. E esta imagem da sociedade pode alimentar-se das experiências concretas que se tem dessas várias actividades. No entanto, não é fácil construir uma tal imagem; o problema que se enfrenta aqui é o dos meios de percepção da diferenciação funcional. Existem, também a este respeito, discursos; existem maneiras de actuar e de falar que poderão ser associadas a um sistema diferenciado em particular. Mas trata-se de uma realidade bastante abstracta e difícil, para muitos, de se percepcionar. Voltamos aliás a um raciocínio já anteriormente proposto: quem participar activamente, com algum grau de autonomia e de responsabilidade em actividades funcionalmente diferenciadas terá algumas possibilidades de reconstruir, a partir de indícios pouco 
visíveis ou pouco acessíveis aos leigos (notícias pontuais, conversas, consulta de documentação especializada), alguma visão de conjunto e actuar em função desta visão. Mas apenas uma minoria beneficiará destas condições. Revestem assim grande importância as oportunidades mais concretas de se experienciar a diferenciação funcional. Voltamos assim, entre outros dispositivos, ao espaço.

A questão que cumpre abordar agora é: qual o possível contributo do espaço - e referimo-nos agora ao espaço tal como resulta da diferenciação funcional, discutido na secção anterior - na construção de colectivos? Poderão distinguir-se em particular três contributos.

No seguimento das reflexões que se acaba de tecer a propósito da construção da sociedade que pode resultar da própria diferenciação funcional, deve aqui examinar-se o possível papel das manifestações espaciais desta. Verificou-se, na secção anterior, que as organizações que concretizam materialmente as actividades funcionalmente diferenciadas, pelo menos na época que se tem qualificado de modernidade "sólida", são regra geral solidamente implantadas territorialmente. As cidades de média dimensão poderão, pela sua disposição topográfica, dar uma boa visibilidade às várias funções diferenciadas: o governo civil representando o Estado central, a Câmara municipal a unidade territorial do Estado mais próxima, vários serviços públicos as grandes funções do Estado: tribunais, esquadras de polícia, hospitais, etc. As escolas, eventualmente as universidades e as bibliotecas, representam a ciência; os museus e salas de espectáculo a arte; as ruas de comércio, mercados e zonas industriais a economia. Em cidades de maior dimensão, a multiplicidade das funções representadas e a dispersão dos edifícios poderão diminuir este potencial semântico da topografia urbana $^{21}$. E deverá ter-se em conta o facto de a simples visão de um edifício ainda ser uma base muito ténue para que se forme uma noção das actividades que dentro deste se desenrolam. Esta noção exigirá provavelmente experiências de contacto directo com estas actividades. Mas, seja como for, a imagem da cidade poderá, de facto, suscitar uma percepção do que é um colectivo caracterizado pela diferenciação funcional. Uma limitação é que a imagem concreta apenas abrange uma localidade, quando as actividades diferenciadas têm um âmbito bem mais amplo. No entanto, esta inserção da cidade neste âmbito mais amplo é visível no espaço, na forma de estradas e de vias-férreas. Porém, além de não serem já mais do que indícios ópticos desta inserção da cidade num mundo social mais vasto, resta determinar os contornos deste mundo mais vasto: país? região? continente? mundo ${ }^{22}$

Evocaram-se até agora experiências de visualização das diferenças e proximidades entre as funções. A imagem das cidades, ou eventualmente a comparação entre cidades ou entre regiões, poderão sugerir ainda outras noções do que a de uma diferenciação funcional harmoniosamente coordenada. Distâncias extremas ou impossibilidades materiais de se passar de um sector para o outro poderão proporcionar experiências de desfasamentos entre sistemas.

Uma segunda maneira de o espaço funcionalmente diferenciado contribuir na construção de colectivos diz respeito aos sistemas diferenciados considerados separadamente. Na medida em que um sistema opera em organizações que circunscrevem, materialmente, espaços bem delimitados, os que são chamados a participar no seu funcionamento poderão mais facilmente, na prática, identificar e reproduzir as particularidades da actividade em causa. É um mecanismo que é utilizado de maneira consciente em empresas, escolas, casernas, etc. Poderá funcionar até para apoiar formações avançadas, desde que se reservem espaços sucessivos para actividades cada vez mais especializadas. Este mecanismo pode completar outros dispositivos, especificamente destinados a formar determinadas pessoas, nomeadamente no seu relacionamento com outras pessoas. Mas também pode ter efeitos em contextos onde os modos de relacionamento se criam essencial ou unicamente na interacção entre as pessoas. Um exemplo poderá ser a circulação rodoviária. As relações entre automobilistas são as que se praticam na estrada, numa aprendizagem colectiva que tem como único dispositivo a delimitação do espaço formado pela estrada. É conhecida uma consequência deste mecanismo: dado que, na estrada, as pessoas não se vêem umas às outras, ou apenas fugazmente, as interacções são processadas como relacionando carros e não pessoas.

\footnotetext{
21 Sobre este, em geral, ver Ferreira (2004).

22 Existe uma abundante literatura infantil apresentando à criança as várias actividades que se verificam numa cidade, que são construídos precisamente para fomentar esta aprendizagem da sociedade moderna.
} 
Finalmente, devem considerar-se as virtualidades do que foi aqui chamado espaço público no sentido restrito. $\mathrm{O}$ que acontece nestes espaços públicos pode ser analisado à luz de um quadro teórico defendido noutro artigo (Guibentif, 2007a), segundo o qual a realidade social merece ser abordada separadamente sob o ângulo das instâncias e sob o ângulo do agir. Todos os níveis de construção do espaço até agora estudados podem ser considerados como constitutivos de instâncias, isto é, de sequências de acções conectadas, e conectandose porque inteligíveis. Na modernidade, a nossa noção do espaço constrói-se a partir da observação de um amplo leque de rotinas, de funcionamentos, de hábitos, desde a circulação dos transportes públicos às operações de manutenção, passando pelas rotinas de circulação de particulares, e incluindo o funcionamento mais longínquo de repartições administrativas com responsabilidades em matéria de topografia, de ordenamento do território ou de sinalização. Fazem parte - poder-se-ia dizer, são um componente necessário - destes espaços públicos os "transeuntes" passeando ou passando pelo local, simplesmente porque era necessário passar.

O conceito de instância obriga a dedicar mais atenção a este último, e essencial, componente: será que as actividades que consistem em passar pelo - eventualmente parar no - espaço público podem ser consideradas como formando uma instância? A resposta pode ser afirmativa. Primeiro critério: este conjunto de actividades pode ser delimitado. Em primeiro lugar, de maneira negativa, por oposição às actividades diferenciadas das organizações e dos sistemas funcionalmente diferenciados. Esta delimitação é, aliás, bastante nítida na modernidade sólida, pois, como vimos, essas actividades desenrolam-se em zonas claramente circunscritas territorialmente. Em segundo lugar, de maneira positiva, pela designação de zonas de passagem intensa. Esta delimitação já é mais difícil de caracterizar. Não é possível traçar fronteiras nítidas, mas apenas focos centrais a partir dos quais a instância, por assim dizer, perde consistência. Em contrapartida, estes pontos centrais são muito precisamente situados, em virtude do mapeamento produzido pelo saber geográfico. Segundo critério: as actividades são susceptíveis de se relacionarem umas com as outras, uma fazendo sentido para a outra. Só que este sentido é determinado essencialmente pela relação com o local: sabemos todos que estamos neste pre- ciso local porque podemos e queremos estar aqui. Um outro elemento, que foi bem identificado por autores como Simmel e Goffman: uma certa forma de manter uma distância em relação aos outros, de atenta desatenção. Mas também formas partilhadas de nos orientar e movimentar neste espaço. $\mathrm{E}$ uma consciência partilhada, embora nunca completa, de que o espaço que partilhamos está posto à nossa disposição como resultado de todo um complexo de actividades e que, segundo as ocorrências, poderemos, uns e outros, solicitar que estas actividades sejam efectivamente cumpridas (dirigindo-nos a um guarda, um funcionário da câmara, um agente de limpeza, um polícia, etc.). Poderá acrescentar-se um elemento mais difícil de se captar e no entanto essencial: uma certa atenção, também partilhada, pelo lugar. Pelo seu aspecto próprio; pelo que nele acontece; e pelo que nele aconteceu. Esta atenção pelo lugar corresponde, aliás, também, a actividades infra-estruturais, de manutenção de monumentos, de construção de edifícios com a preocupação do seu impacto visual; de autorização ou tolerância de actividades de espectáculo; de organização de desfiles e outros eventos; de tradução na forma de monumentos de elementos de história do colectivo. Esta componente do espaço público adquire particular visibilidade através de uma actividade que se pode parcialmente diferenciar das restantes que têm lugar no mesmo espaço: o turismo. Para o qual são editados mapas e guias e organizadas visitas a monumentos considerados como sendo de particular interesse. Significativamente, no entanto, o turismo não se deixa diferenciar categoricamente de outras formas de estar na cidade. Qualquer um pode, por momentos, adoptar um olhar de turista.

No contexto de uma realidade social funcionalmente diferenciada, poderemos interrogarmo-nos sobre as possíveis funções desta instância, que é o espaço público. Funções que poderão motivar parcialmente as actividades de manutenção, e que poderão estar ocasionalmente presentes também na consciência dos que participam actualmente na instância. Podem ser evocadas três. Uma é a de garantir um espaço intermédio entre as actividades funcionalmente diferenciadas. Os sistemistas falariam em articulação estrutural (structural coupling $)^{23}$. Cada sistema e organização funcionam segundo a sua lógica própria, ignorando em larga medida o funcionamento das outras. O espaço

\footnotetext{
$\overline{23}$ Sobre este conceito, ver em particular Luhmann (1993).
} 
público é o espaço onde podem circular e misturar-se informações provenientes dos vários sistemas, aumentando as hipóteses de serem aproveitadas complementaridades e de serem reduzidas incompatibilidades. Outra função é a de legitimar a ordem constituída pela composição dos vários sistemas, incluindo em particular a macroorganização do Estado. Enquanto as pessoas, livres de circular e permanecer em determinados locais, ali passearem com alguma regularidade, e não manifestarem descontentamento, o que acontece nas ruas significa paz social, isto é, aceitação global da ordem da qual este espaço público faz parte. Finalmente, poderá considerar-se a instância espaço público, este cruzar de desconhecidos num lugar onde todos vieram porque ali queriam estar, como um dispositivo de formação para um determinado papel, neste caso o papel de cidadão.

Podemos assim completar as respostas à questão do actual papel do espaço na construção de colectivos. O próprio espaço, pelo menos nalguma fase histórica, participou na construção de uma sociedade composta por um conjunto complexo de instâncias. Primeiro, contribuindo para a diferenciação de um conjunto de instâncias especializadas, pela territorialização das organizações que as sustentam. Em segundo lugar - como acabámos de ver - definindo, pela forma como é organizado por outras instâncias especializadas, espaços nos quais se tece uma instância social específica, destinada nomeadamente a facilitar a articulação entre as restantes. Em terceiro lugar, oferecendo, pelo menos em certos lugares, imagens de conjunto desta sociedade complexa. E podemos acrescentar aqui um elemento a esta imagem de conjunto que, numa primeira abordagem, ainda não realçámos: a rua como espaço identificador dessa instância intermédia ${ }^{24}$.

Convinha naturalmente designar a referida instância intermédia por um termo específico. Não se trata da "sociedade", pois convinha reservar esta designação para uma realidade que abranja as várias instâncias. Seria mais indicado falar do "público", devendo ter-se o cuidado de distinguir conceptualmente este "público" como instância social, isto é, conjunto continuado de actividades, do "espaço público" que constitui uma condição material de funcionamento da instância. De notar que ambos são "construções sociais": o "público" pela maneira que cada pessoa tem, no espaço público, de percepcionar a sua presença ou actuação neste espaço e a relação destas com as presenças e actuações de outras pessoas. O espaço público, por um conjunto de medidas materiais e simbólicas que resultam de actividades de organizações e sistemas diferenciados, coordenadas por uma vontade de governo em abrir um espaço para o público.

Enquanto instância, o público não deixa de padecer de uma certa indefinição. Esta não o impede de existir (é o que se pretende captar com o conceito de instância: não se limitar - como o sugere o conceito de sistema - ao que é nitidamente diferenciado). Mas deixa aberta a possibilidade de novas diferenciações, com efeitos imprevisíveis. Podem referir-se três destas possíveis diferenciações. Uma consiste em precisar o âmbito territorial. É o que se passa, por exemplo, quando determinadas zonas das cidades são consideradas como "bairros problemáticos" que convém evitar. Outra consiste em delimitar em termos de pessoas. É o que acontece quando se instalam critérios permitindo opticamente - único tipo de critério possível numa instância onde a única comunicação obrigatória é visual - uma diferenciação entre pessoas que se consideraria a priori como fazendo parte do público e as que dele não fazem parte. Outra ainda, de natureza muito diferente, consiste em reduzir a definição funcional do espaço; com efeito, uma função do que se faz no espaço público pode ser separada das outras: a função de circulação, ou mais especificamente ainda, de circulação entre espaços funcionalmente diferenciados. Estes processos de rediferenciação poderão ser favorecidos por tendências de estabilização da instância, que requer, enquanto instância, alguma diferenciação. Mas poderão ter efeitos sem relação directa com estas necessidades de funcionamento da instância, no plano das funções desempenhadas pelo público. As diferenciações territoriais e pessoais prejudicam as funções de formação para a cidadania. A diferenciação territorial reduz o potencial legitimador. A diferenciação funcional, se chegar ao ponto de marginalizar outras funções que não a da circulação entre instâncias, poderá, paradoxalmente, reduzir o potencial de articulação estrutural entre essas outras instâncias. Pois essa articulação estrutural 
apenas tem hipótese de ter lugar se, no público, acontecer mais do que apenas circulação.

Convém agora abordar os espaços diferenciados sob o aspecto do agir. Uma primeira questão a abordar brevemente é a de saber até que ponto o espaço em si pode motivar um agir, isto é, a emergência de uma subjectividade ou de uma força. Uma situação a referir em primeira linha é a experiência da falta de espaço, que pode ser individual ou colectiva, e traduzir-se em casos extremos em agressões ou na destruição de elementos do meio circundante. Outra é a atracção pelo espaço, que pode motivar deslocações. Outra ainda, que poderemos chamar inspiração, é a que acontece quando a configuração e o aspecto de um lugar estimula uma acção ou comunicação que não seja uma deslocação. Em todos estes casos, será de aprofundar o que contribuiu para a génese da experiência motivadora do espaço. Pode presumir-se que outros factores, designadamente sociais (conflitos latentes, dinâmicas integradoras ou desintegradoras, etc.) terão também grande importância. O desafio, para a sociologia do agir, será reconstituir esta configuração de motivos, ou, mais precisamente, de como o processo de construção do espaço conduziu a dinâmicas perceptíveis sob o aspecto do agir.

Nestas reflexões exploratórias, considerar-se-ão os casos nos quais um agir se manifesta num ou em vários espaços - tais como coexistem em contextos funcionalmente diferenciados - estando no entanto sustentado por uma dinâmica que transcende estes espaços. Consideremos primeiro as organizações e os sistemas funcionalmente diferenciados. Podem admitir-se duas situações. Nos espaços onde funcionam, processa-se um determinado tipo de actividade. Esta actividade pode desenrolar-se de maneira rotineira. Nesta actividade, por momentos, pode emergir uma certa inspiração ou criatividade, revelando que se formou uma força de iniciativa subjectiva. Ou também - caso que Max Weber tinha em mente ao falar do "carisma" - uma capacidade de influência sobre os outros, para além das suas competências formalmente reconhecidas. $\mathrm{O}$ agir, nestes casos, vai no sentido da função da instância. Poderá dar mais força ao seu funcionamento, e, desta forma, conduzir a uma expansão espacial ou uma outra manifestação espacial ${ }^{25}$. Mas também podem surgir forças, cuja raiz pode estar dentro ou fora destes espaços, sem relação directa com a finalidade do funcionamento habitual. Pode pensar-se em particular em conflitos, como os que surgiram, com o avançar da industrialização, entre o operariado e as direcções das fábricas. Não se inscrevendo na linha do funcionamento habitual da instância, é menos provável que tais dinâmicas internas se traduzam no espaço de uma maneira duradoira.

Encontramos uma situação muito diferente no espaço público. Este, com efeito, não tem uma função específica claramente definida, e foi concebido com fisicamente aberto, em parte para poder acolher actividades diversas. Uma primeira intensificação das actividades do espaço público seria a situação seguinte: um acontecimento atrai a atenção de alguns, e gera-se uma movimentação na qual se intensifica a experiência de "estar aqui para ver qualquer coisa", nomeadamente pela experiência de que outros, os que se deslocam ao meu lado, rumo ao lugar "onde isto se passa", fazem a mesma experiência. Uma outra corresponderia ao processo que conceptualiza Foucault, dos "sujeitados" que se convertem em "sujeitos", reapropriando-se, negando-o, o papel que deveriam desempenhar. Evocou-se a função legitimadora do espaço público. Nele, o público, ao circular pacificamente, mostra uma aceitação generalizada da ordem vigente. Existem circunstâncias nas quais parte das mesmas pessoas tomam consciência do potencial deste dispositivo em ser reutilizado em sentido contrário: tornar visível algum descontentamento com a ordem que criou o lugar. Tais manifestações podem conduzir a alterações físicas do espaço, que poderão ter importância em outras ocasiões, favorecendo ou eventualmente inibindo novas manifestações. Mas o interessante é que o espaço instalado como espaço público, pode, em tais circunstâncias, revelar-se como fisicamente apropriado e passar, desta maneira, a revestir, enquanto espaço, embora fisicamente inalterado, um novo significado. É o que aconteceu com as ruas e praças em Paris na Revolução Francesa; é o que se passou em Lisboa em 1974. Lugares construídos sem ter esta finalidade, acolheram manifestações às quais deram visibilidade e que, inversamente, deram ao lugar um novo significado. Ou seja:

\footnotetext{
${ }_{25}$ Certas construções arquitectonicamente ousadas, empreendidas por grandes empresas, poderão resultar de dinâmicas internas desta natureza; ou, a partir do momento em que uma empresa criou um precedente, podem ser planeadas para sugerir ao exterior a realidade de forças internas.
} 
o espaço público, desde que haja público que o ocupe actualmente, é um espaço que torna possível a formação de agir, sem que as finalidades deste agir estejam estreitamente predeterminadas. Poder-se-ia ir um pouco mais longe, e reconhecer que a experiência de tais manifestações de força poderá condicionar e sustentar o funcionamento do público enquanto instância ${ }^{26}$. Entre as vãs expectativas que vagamente animam o transeunte, também existe a perspectiva de alguma manifestação política.

Convém mencionar também uma situação que combina as duas ordens de fenómenos que se acaba de discutir. Com se viu, o espaço funcionalmente diferenciado das organizações não é adequado à expressão de forças não coincidentes com a função da organização. Na medida em que forças, por exemplo geradas por situações de conflito, se traduzem nalguma capacidade de acção, é possível que se procure dar-lhes expressão no espaço mais acolhedor que é o espaço público. Poderá, então, assistir-se a uma consonância entre sensibilidades até à data latentes no espaço público, e as que vêm expressar-se nele, oriundas de outras instâncias. Poderá analisar-se nestes termos a forma como o movimento operário, saindo das fábricas, ganhou força e marcou fisicamente o espaço público entre o fim do século XIX e as primeiras décadas do século Xx. Um raciocínio semelhante poderia ser aplicado ao movimento feminista desde os anos 1960.

Em conclusão, diremos que, em contextos funcionalmente diferenciados, o espaço contribui de maneiras diferentes à construção de colectivos, conforme consideramos os seus efeitos sob o ângulo das instâncias ou sob o ângulo do agir. Sob o ângulo das instâncias, participa na própria diferenciação funcional, marcando a diferença entre actividades diferenciadas, e oferecendo imagens de conjunto da configuração de uma sociedade diferenciada. E fornece o seu substrato, o espaço público, a um tipo de instância sui generis, o público. Sob o ângulo do agir, favorece as energias que vão no sentido das funções reconhecidas das actividades diferenciadas, e trava as que não correspondem a estas finalidades. Em contrapartida, facilita a emergência de forças sociais na medida em que existirem espaços públicos habitados por algum público.

\section{Evoluções recentes}

A terceira modernidade traz alterações a este quadro, em vários planos. Uma primeira é que se reforça a mundialização dos sistemas funcionais. Em particular a economia, que funcionou durante algum tempo estreitamente controlada e fortemente incentivada pelos Estados, ao abrigo das fronteiras destes, passa agora a funcionar à escala mundial. Quanto aos outros sistemas funcionais, a comunicação social e a arte funcionam cada vez mais à escala do mundo, com a crescente intervenção, na produção de conteúdos, de entidades multinacionais, e de personalidades que alcançaram uma reputação mundial e que actuam em função disto. No caso do direito, as práticas nacionais são entendidas cada vez mais como práticas do direito-mundo, dando alcance mais amplo a operações que são de relevância em princípio nacional. De todos os sistemas funcionais, talvez seja a ciência que menos muda nesta fase, porque já tinha evoluído muito no sentido da internacionalização nos períodos anteriores.

Os sistemas que menos se internacionalizaram são os Estados. Os avanços mais significativos neste sentido consistem na formação de blocos regionais, como é o caso da União Europeia. Estes não alteram muito a realidade dos territórios, passando os territórios nacionais a integrar territórios de ordem superior. Tornam, sim, mais abstracta a noção de pertença a um mesmo colectivo, entre as pessoas originárias dos vários Estados, pois dificilmente se pode ter uma noção concreta do meio no qual vivem outras pessoas. Tão importante ou mais é o facto de, pelo menos na Europa, o conjunto de Estados, enquanto tal, não se dotar de espaços públicos que teriam a vocação de acolher manifestações que reúnam uma parte, mesmo que pequena, da população da entidade supranacional. Enquanto que em Estados como Portugal ou França, existem locais onde poderão convergir representações importantes da população nacional, ao nível europeu, tais locais são exíguos e dispersos ${ }^{27}$.

Quanto aos sistemas funcionalmente diferenciados, poderão ainda registar-se indícios da seguinte evolução. Multiplicam-se as organizações híbridas, que deixam de sustentar prioritariamente determinado sistema. Esta evolução traduz-se na

\footnotetext{
${ }^{26}$ Sobre espaço público e memória política, ver Ferreira (2004), pp. 169 ss.

${ }^{27}$ Seria interessante analisar nesta perspectiva a localização e a arquitectura do Parlamento Europeu em Estrasburgo. Não se pode dizer que sejam apropriadas para valorizar grandes concentrações.
} 
arquitectura, onde se deixou de pretender encenar determinadas funções, para dar visibilidade, apenas, à adequação do edifício a um funcionamento organizacional eficiente e de qualidade. Assiste-se assim a um apagamento das marcas mais visíveis da diferenciação funcional. Uma evolução que também é favorecida no espaço virtual criado pelas novas tecnologias de comunicação. As diferenças entre os sites que visita o internauta são certamente menos nítidas do que as que existiam entre as repartições onde anteriormente a pessoa se deslocava, diferenças que se manifestavam claramente, além de outros critérios (medidas de segurança, cultura de atendimento, decorações, etc.) na distância geográfica entre as várias instalações.

Dentro dos Estados, várias evoluções tendem a reduzir os espaços que podem ser qualificados de públicos. Umas destas evoluções implicam uma redução material dos espaços livremente acessíveis. É o caso da aparição de condomínios fechados. Estes espaços não só deixam de ser acessíveis a todos, como são experienciados, pelos que estão autorizados a entrar, como espaços onde os que se encontram pertencem a um determinado grupo. Poderia referir-se também, nesta categoria, os terrenos de golfe instalados em zonas antigamente acessíveis ao público, terrenos cuja natureza privada é aliás muito visivelmente assinalada por um relvado característico. A instalação de centros comerciais não reduz materialmente o espaço; no entanto, altera profundamente a experiência que deste se faz. Com efeito, o espaço que separa as várias lojas passa a ser reduzido a uma única função, a de se deslocar de uma loja para a outra. A própria frequentação deste espaço, aliás, deixa de ser apenas uma experiência dos que lá andam, para se tornar um valor económico, condicionando o preço das rendas que a entidade proprietária do centro poderá exigir dos donos das lojas. Com ou sem a percepção deste mecanismo, os que neste espaço se cruzam tenderão em percepcionar-se uns aos outros cada vez mais exclusivamente como consumidores. Outra evolução ainda é a que consiste em reduzir drasticamente as medidas de manutenção de determinados espaços muito frequentados. Pode pensar-se em estações de comboio que, em vários países europeus, deixaram de ter serviços de atendimento ao público, substi- tuídos por máquinas, e passaram a ter aspecto de lugares abandonados. Poder-se-ia acrescentar ainda o seguinte. Muitas diligências exigiam, até agora, uma deslocação por espaços que, muito utilizados por muitas pessoas, se tornavam necessariamente públicos. Cada vez mais, estas mesmas diligências são executadas recorrendo-se às novas tecnologias de comunicação ${ }^{28}$. Reduz-se assim a frequentação dos espaços, que, logo, deixam de ser experienciados como efectivamente públicos.

A terceira modernidade é uma época na qual as oportunidades de experiência do espaço através de ligações que se pode ter com organizações se encontram também reduzidas. Por um lado, as relações entre pessoas e organizações tendem em ser menos duradoiras, o que reduz as possibilidades de uma pessoa se apropriar nalguma medida do espaço da organização à qual pertence. Por outro lado, nas organizações, existem tendências em desapertar os vínculos entre funções e espaços, animando-se as pessoas a trabalhar em diversos lugares e a terem mais mobilidade espacial no desempenho das suas funções. O que se tornou compatível com o funcionamento da organização graças às novas tecnologias de comunicação, que garantem uma acessibilidade permanente da pessoa empregada, e lhe permitem, em muitos casos, deslocar-se transportando o seu instrumento de trabalho. Esta característica da nossa época, que conduziu Bauman (2000) a propor a metáfora da "modernidade líquida" não se aplica a toda a realidade social. Existem, nas margens desta modernidade líquida, zonas marcadamente territorializadas. No espaço europeu, o caso mais emblemático destes dispositivos espacializados são os campos para onde são encaminhados os imigrantes clandestinos. Mas pode estabelecer-se uma relação entre a forte identificação territorial destes dispositivos e a crescente "desespacialização" promovida noutros âmbitos. De alguma forma, uma compensa a outra ${ }^{29}$.

Finalmente, não podemos deixar de recordar que, desde a modernidade, as grandes estruturas espaciais que têm sido discutidas aqui, coexistem com estruturas periféricas ou privadas, que obedecem a outras lógicas, e podem evoluir de forma ainda diferente. E que, até à segunda modernidade, se mantêm espaços de proximidade nos quais as inte-

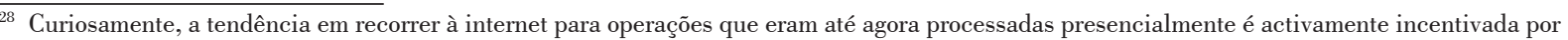
campanhas promocionais apoiadas financeiramente pela União Europeia.

29 Sobre as relações entre componentes sólidos e líquidos da realidade social, ver Guibentif (2007b).
} 
racções são geridas em larga medida imediatamente pela pessoas envolvidas. Permaneceram assim espaços nos quais, segundo modalidades variadas, se assiste a processos circulares de construção do espaço pelas relações sociais, e destas pelas práticas espaciais. Pode admitir-se que os espaços de sociabilidade tradicional se reduziram. Os espaços familiares aparecem cada vez mais estruturados por dispositivos promovidos no mercado de consumo, em função de critérios de qualidade e de conforto de utilização que são definidos longe desses contextos. As interacções processam-se em crescente medida por meios electrónicos, o que tira relevância à dimensão do espaço na sua definição. Ou seja, pode presumir-se que diminui a quantidade de situações nas quais as pessoas experienciam imediatamente o espaço como definidor das relações com os outros, e as relações como definidoras de espaços, ou seja a sua capacidade de dar sentido a espaços e relações na articulação prática entre estas duas realidades.

Em suma, a possibilidade de construção de colectivos pelo espaço, na época actual, está a evoluir profundamente. Estas evoluções são diversas e poderão ter efeitos muito diferentes. É, por isso, melindroso avançar qualquer prognóstico. Algumas tendências merecem no entanto ser realçadas. Uma é que o espaço poderá estar a perder parte do seu potencial semântico: cada vez menos oferece uma imagem orientadora da realidade social. Porque esta se processa cada vez mais em circuitos globais desmaterializados. E porque as implantações organizacionais locais são cada vez menos funcionalmente identificadas. Outra é que o público aparece como uma instância ameaçada pela redução do espaço de que necessita. Outra ainda é que lugares onde, na história recente, surgiram subjectividades e forças criativas, poderão perder progressivamente este potencial. Finalmente, poderá ser que, perdendo desta forma relevância na construção de colectivos, o espaço em si deixe progressivamente de poder ser percepcionado. Suspeito que é esta a intuição que motiva os artistas que, actualmente, tratam o tema do espaço ${ }^{30}$. Vale a pena os sociólogos estarem atentos. Podem ter, ao associarem-se a estes trabalhos, uma feliz oportunidade de contribuir para esforços locais de reapropriação do espaço, pondo em prática uma diferenciação funcional construtiva.

$\overline{{ }^{30} \text { Neste sentido, Guedes (2006), p. } 62 .}$ 


\section{Referências}

AgIER, Michel (2008), “O 'acampamento', a cidade e o começo da política”, in: CORDEIRO / VIDAL (2008), pp. 17-26.

Arnaud, André-Jean (1991), Pour une pensée juridique européenne, Paris, PUF.

Bauman, Zygmunt (2000), Liquid Modernity, Cambridge, Polity Press.

Bourdieu, Pierre (1994), "Espace social et espace symbolique", in : Raisons pratiques. Sur la théorie de l'action, Paris, Seuil, pp. 13-29.

- (1997), Méditations pascaliennes, Paris, Seuil.

Chantraine, Pierre (1968), Dictionnaire étymologique de la langue grecque, Paris, Klincksieck, 1984 (ed. orig.: 1968).

CheVALIER, Louis (1978), Classes laborieuses et classes dangereuses, Paris, Librairie générale française (la éd.: 1958).

Commaille, Jacques (2000), Territoires de justice. Une sociologie de la carte judiciaire. Paris, PUF.

CordeIro, Graça Índias, VIDAL, Frédéric (orgs.) (2008), A rua. Espaço, tempo, sociabilidade, Lisboa, Livros Horizonte.

DoRTIER, Jean-François (1998), Les sciences humaines. Panorama des connaissances, Auxerre, Éditions Sciences Humaines.

Ferreira, Vítor Matias (2004), Fascínio da cidade. Memória e projecto da urbanidade, Lisboa, Ler Devagar.

FinLey, Moses L. ([1970]1980), Les premiers temps de la Grèce, Paris, Flammarion, 1980 (ed. orig. Londres, 1970).

- ([1983]1985), L'invention de la politique, Paris, Flammarion, 1985 (ed. orig.: Cambridge, 1983).

Foucault, Michel ([1966] s.d.), Les mots et les choses, Paris, Gallimard, 1966; trad. port. As palavras e as coisas, Lisboa, Edições 70, s.d.

- ([1978] 2004), Sécurité, territoire et population (cours au collège de France 1977-1978), Paris, Gallimard/Seuil.

(s.a.) (1989), Gilgamesh (Versão de Pedro Tamen do texto inglês de N. K. Sandars), Lisboa, Vega.

Goffman, Erving (1983), "The Interaction Order", American Sociological Review, 48, pp.1-17.

Gonçalves, Maria Eduarda, Maria Manuel Leitão Marques (2001), António Carlos dos Santos, Direito económico, Coimbra, Almedina (4..$^{\mathrm{a}}$ ed.; 1. ${ }^{\mathrm{a}}$ ed. 1991)

GuedEs, André (2006), a 2ois, Tapada da Tojeira, CENTA - Centro de Estudos de Novas Tendências Artísticas / Museu de Francisco Tavares Proença Júnior.

Guibentif, Pierre (2001), “A comunicação jurídica no quotidiano lisboeta. Proposta de abordagem empírica à diferenciação funcional", Forum Sociológico n. ${ }^{\text {os }}$ 5/6 (II série), pp.129-161.
- (2005), "Avaliação e Reflexividade - A Prática da Sociologia na "terceira modernidade", Cidades - Comunidades e Territórios, $\mathrm{n}^{\circ} 10$, pp. 94-115.

- (2007a), "Teorias sociológicas comparadas e aplicadas. Bourdieu, Foucault, Habermas e Luhmann face ao direito", Cidades - Comunidades e Territórios, n. ${ }^{\circ}$ 14, pp. 89-104.

- (2007b), "The Liquidity and Solidity of Contemporary Social Reality: the Example of Social Inclusion Policies", in: Přibáň, Jiří (org.), Liquid Society and its Law, Aldershot, Ashgate, 2007, pp. 173-197.

- com Vanda Gorjão e Rita Cheta (2002), Comunicação Social e Representações do Crime, Lisboa, CEJ.

Gusdorf, Georges (1978), La conscience révolutionnaire. Les idéologues (Les sciences humaines et la pensée occidentales - VIII), Paris, Payot.

HABERMAS, Jürgen (1963), "Naturrecht und Revolution", in Habermas, Jürgen, Theorie und Praxis. Sozialphilosophische Studien, Neuwied/Berlin, Luchterhand, 1963 (trad. fr. Théorie et pratique, Paris, Payot, 1975; trad. ingl. Theory and Practice, London, Heineman, 1974).

- (1981/1987), Theorie des kommunikativen Handelns, Frankfurt-sur-le-Main, Suhrkamp, 2 vols, 1981. (trad. fr.: Théorie de l'agir communicationnel, Paris, Fayard, 2 vols, 1987).

Hespanha, António Manuel (1988), "Sábios e Rústicos: A violência doce da razão jurídica", Revista Crítica de Ciências Sociais, n. ${ }^{\text {ss }}$ 25/26, Dezembro de 1988, pp. 31-60.

- (2002), "Os juristas como couteiros. A ordem na Europa ocidental dos inícios da idade moderna", Análise Social n. ${ }^{\circ} 161,2002$, pp. 1183-1268.

- (2003), Cultura Jurídica Europeia. Síntese de um Milénio, Mem Martins, Publicações Europa-América.

IturRa, Raúl (2002), A Economia deriva da Religião, Porto, Afrontamento.

Luhmann, Niklas (1988), Die Wirtschaft der Gesellschaft, Frankfurt /M., Suhrkamp, $356 \mathrm{p}$.

- (1990), Die Wissenschaft der Gesellschaft ("A ciência da sociedade"), Frankfurt am Main, Suhrkamp.

- (1993 / 2004), Das Recht der Gesellschaft, Frankfurt /M., Suhrkamp, 1993 (trad. angl.: Law as a Social System, Oxford, Oxford University Press, 2004).

- (1995), Die Kunst der Gesellschaft, Frankfurt/M., Suhrkamp.

- (1996), Die Realität der Massenmedien, Opladen, Westdeutscher Verlag.

Meeks, Dimitri, Favard-Meers, Christine (1995), Les dieux égyptiens, Paris, Hachette.

Morus, Tomás ([1516] 1952), A Utopia, Lisboa, Guimarães Editores, 1952 (ed. orig. Basileia, 1516).

Panofsky, E. (1975), La perspective comme forme symbolique, Paris, Minuit. 